\title{
The Syntax and Cognitive Motivation of English It-Clefts
}

\author{
Kun Yang ${ }^{1}, \mathrm{Xu} \mathrm{Wen}^{1} \&$ Zhengling $\mathrm{Fu}^{1}$ \\ ${ }^{1}$ Research Center for Modern Linguistics and Second Language Education, College of International Studies, \\ Southwest University, Chongqing, China \\ Correspondence: Kun Yang, Research Center for Modern Linguistics and Second Language Education, \\ Southwest University, Chongqing, China. E-mail: yangkunjordan@126.com
}

Received: May 26, 2014 Accepted: June 17, 2014 Online Published: October 1, 2014

doi:10.5539/ijel.v4n5p59 URL: http://dx.doi.org/10.5539/ijel.v4n5p59

\begin{abstract}
English it-cleft is a constant topic in linguistic study. Previous work on it-clefts resided in their structural and functional aspects and neglected their cognitive basis. This paper is an attempt to consider the form and function of it-clefts within the framework of Cognitive Linguistics. Most previous studies of it-clefts have paid no attention to the status of "it" and "copular be" which is generally believed to be dummy. Following the tenets of Cognitive Linguistics, every form has its own meaning or function. This paper argues that the function of "it" as a pronoun is relative to the cleft clause, which is modified by the clause. "Copular be" performs the function of identifying in it-clefts. The paper then uses the concepts of Recency Effect, figure-ground and grounding theory to account for the information distribution, cognitive motivation of it-clefts.
\end{abstract}

Keywords: it-cleft, motivation, focusing, figure-ground, grounding

\section{Introduction}

It-cleft is generally accepted as a marked syntactic bi-clausal option in English, which expresses a simple semantic proposition in terms of information distribution by placing an element in focal position within the copular matrix clause. The most quoted definition was given by Jespersen (1937/1969, p. 147-8):

A cleaving of a sentence by means of "it is" (often followed by a relative pronoun or connective) serves to single out one particular element of the sentence and very often, by directing attention to it and bringing it , as it were, into focus, to mark a contrast...

It is known that it-cleft is a grammatical device associated with information focus: it enables the user to select (within limits) which element of the sentence will be highlighted. A cleft construction is divided into two main parts: the focus element (or foci) and the background structure which resembles a relative clause. English it-cleft, as Jucker (1996, p. 699) argued, has always been a testing ground for linguistic frameworks: generative in the sixties and early seventies, presuppositional in the seventies and early eighties, functional or discourse analytical in the eighties. And now it imposes an explanatory challenge on Cognitive Linguistics. Most previous work on it-clefts has mainly resided in structured and functional approaches. From a structured perspective, the scholars (Akmajian, 1970; Chomsky, 1970; Gundel, 1977; Higgins, 1979; Delahunty, 1984, etc.) focused on the syntactic structural analysis of it-clefts. Others (Halliday, 1994; Prince, 1978; Quirk et al., 1985; Collins, 1991; Huang \& Fawcett, 1996, etc.) adopted a functional perspective by exploring clefts from their thematic structure and information structure. In this paper, we shall first elucidate the form and function of it-clefts within the framework of Cognitive Linguistics and then using the descriptive apparatus of Cognitive Linguistics explore the cognitive motivations of the basic elements in it-clefts.

\section{An Account of the Basic Elements in It-Clefts}

A construction is generally understood as a form-meaning pairing. To describe a construction fully, one has to specify: (a) the meaning of each component element; (b) how these meanings are integrated to form a composite conception at different levels of organization; (c) how the construction relates to others (its position in intersecting networks of constructions and construction variants (Langacker, 2009, p. 60). From the constructionalist approach, linguistic elements are symbolic units that consist of a specific form paired with a specific meaning. This position implies that each form in a linguistic structure carries a corresponding meaning or meanings. The following part will explore the functions of these basic elements in clefts. 


\subsection{The Subject "It"}

There are two prevailing views to account for "it" in it-clefts in the literature. One regards the pronoun "it" in it-clefts as "empty it" or "dummy it" which is semantically non-referential or semantically null cipher (e.g., Delahunty, 1984; Collins, 1991; Huang, 2003). Another view holds that "it" is a referring pronoun demonstrating cataphoric reference. The latter position seems to be more popular than the former one (e.g., Huddleston, 1984; Gundel, 1977; Quirk et al., 1985; Hedberg, 1990), which is commonly labelled as "the referential account of "it"' since it is in full accordance with one of the basic tenets of Cognitive Linguistics - any form takes its meaning. The regarding of "it" as a dummy "it" is untenable in that some items like "this, that, these, those, etc." could possibly be used to take place of "it" as the subject of clefts (e.g., Quirk et al., 1985; Hedberg, 1990; Huang, 2003). In this paper, we argue that it is the identifying function of it-clefts that makes this referential interpretation of "it" possible. Following this point, the pronoun "it" and cleft clause form a "discontinuous" unit which serves the same function like a description. This characteristic makes it-clefts have much in common with wh-clefts and all-clefts. As in (1):

(1) a. It is CHAMPAGNE that I like.

b. What I like is CHAMPAGNE.

c. All I like is CHAMPAGNE.

Examples in (1) share many similarities: the same proposition, the same presupposition and more importantly with the same function of highlighting the postcopular element "Champagne". (1a), (1b) or (1c) differs from each other when the syntactic structure is concerned. Mainly for this reason, many researchers point out that (1a) is the source form to generate (1b) and (1c) by negotiating with the cleft clause or embedded clause, wherein the cleft clauses or embedded clauses undergo ways of nominalization.

\subsection{The "Copular Be"}

The constituents "copular be" in clefts are always treated together with "it". Less attention was drawn to "it" itself. The following part will elaborate the exact role that "copular be" plays in it-clefts.

\subsubsection{The Functions of "Copular Be"}

"Copular be" in it-clefts is traditionally regarded as a meaningless element inserted merely for grammatical purposes in specific environments. It is always treated with "it" and "it be" as a whole serves as a unified unit. Most scholars treat "it" and "be" of the superordinate clause as a grammaticalized part (e.g., Huddleston, 1984, p. 464; Collins, 1991, p. 52; etc.), whose role is a focusing marker with the role of "be" being neglected. However, this position runs counter to the basic claim of cognitive grammar that every form should take some specific meaning or meanings. As we can see, some scholars (Halliday, 1994, p. 119-124; Collins, 1991, p. 37-40) in systemic functional tradition have identified two major types of structures marked by verb "be", namely, attribution vs. identification, as shown in (2) and (3) (Collins, 1991, p. 37):

(2) a. The youths on bikes are a vicious gang.

b. A vicious gang are the youths on bikes.

(3) a. The youths on bikes are the local gang.

b. The local gang is the youths on bikes.

The sentences in (2) are the attributive type which has a "mention some" feature, that is to say, with a property being ascribed to the subject "the youths on bikes". In contrast, the sentences in (3) are the identifying type, with "the local gang" being used to define the identity of "the youths on bikes". "The local gang" is the "identifier" and "the youth on bikes" is "the identified" (Collins, 1991, p. 37). These properties could be inevitably evoked as evidence to distinguish pseudoclefts from some superficially similar attributive constructions.

(4) a. What Tom offered Sue was too sweet.

b. What Tom offered Sue was unknown.

c. What Tom offered Sue was a puzzle.

d. What he said was laughed at.

Examples listed in (4) cannot be delimited as clefts according to Traugott (2008)'s characterization of clefts. Traugott (2008, p. 150) may consider (4a, b) as ascriptive adjective; (11d) as the ascriptive passive, and (4c) as non-referential nominal. In Collins (1991)'s analysis, the sentences (4a, b, d) do not belong to clefts based on the same reason that Traugott (2008) has proposed. Moreover, two detailed operating rules are added: on one hand, 
in pseudo-clefts, the precopular part and the postcopular can be reversed, but (4a, b, d) do not have this function; on the other hand, pseudoclefts can always be "cleaved" but these examples cannot. Nonetheless, Collins' account of the example (4c) differs from Traugott's. Collins (1991, p. 38) argues that sentence (4c) is ambiguous between an identifying reading and attributive reading: on the identifying reading, "a puzzle" is understood in a substantive, referential sense like (a crossword puzzle), and on the attributive reading, the embedded wh-clause is interrogative and "a puzzle" has an adjective force.

Collins (1991)'s analysis has wisely taken "discourse" into account; therefore his arguments seem not to be reluctant to accept. In this paper Collins' view is largely adopted. It is suggested that the function of "be" determines the distinction between the two types of superficially similar sentences. It is the "identifying/specificational" feature marked by "be" that makes a sentence a real pseudocleft. This "identifying" feature can also be feasibly applied to test the eligibility of it-clefts. See the example discussed by Jespersen (Lambrecht, 2001, p. 470):

(5) It is the country that suits her best.

This sentence is a well-quoted example which is ambiguous between a cleft and non-cleft reading. It can be construed in different ways with regard to the discourse context in which it might emerge from. The first construal is that the relative clause is restrictive with the function of modifying the postcopular noun phrase "the country". The speaker is to convey the predicate: the country that suits her best. In contrast, the second construal is similar to the sentence: the country suits her best (others not). In this reading, the noun phrase "the country" is the focus of the overall sentence, which is stressed phonetically.

This specific feature of it-clefts seems possibly to account for the invalidity of proverbial expressions as clefts, though these expressions are superficially similar to it-clefts. See the following examples (Collins, 1991, p. 40):

(6) a. It is an ill bird that fouls its own nest.

b. It is a poor heart that never rejoices.

Idioms are a conventional inventory of language, the meaning of which cannot be predicted or at least entirely predicted, so we say that a construction is a schematic idiom. Like examples in (6), these idioms, which are superficially similar to it-clefts, are undoubtedly classified as non-clefts for their attributive feature. Now, let's consider the corresponding "pseudoclefts" of (6) with the same propositional meaning and the copular "be" functions the same as (6).

(7) a. The bird that fouls its own nest is an ill bird.

b. The heart that never rejoices is a poor heart.

It should be noted that these seemingly "pseudoclefts" might have other counterparts but it would not affect my standpoints. As in (7), (a) and (b) might be the corresponding "pseudoclefts" of (6a) and (6b). These so-called "pseudoclefts" in (7) clearly present the "attributive functions" of the idioms in (6). That is to say, the postcopular part is as a way of saying something more without any identifying or specifying force. Like (2), a property is ascribed to the subject "the bird that fouls its own nests" in (7). Thus, it is again the identifying feature of "copular be" that delimits clefts from other superficially resembled constructions.

\subsection{2 "Copular Be" and the Agreement Phenomenon}

The flexibility of it-clefts can be seen in the ease with which different parts of a sentence can be highlighted, as shown in (8):

(8) Xiao Yang met your sisters in the zoo yesterday. (Non-cleft sentence)

a. Subject as the foci

It was Xiao Yang that met your sisters in the zoo yesterday.

b. Object as the foci

It was your sisters that Xiao Yang met in the zoo yesterday.

c. Adverbial (position) as the foci

It was in the zoo that Xiao Yang met your sisters yesterday.

d. Adverbial (time) as the foci

It was yesterday that Xiao Yang met your sisters in the zoo.

Most parts of a sentence can be highlighted including subject, direct object, indirect object, adjunct (of different kinds), complement, etc. But the predicate (verb), as Quirk et al. (1985, p. 1385) suggested, does not occur at all as the foci, just as it cannot be questioned. 
(9) ?? It was meeting that I did to your sister in the zoo yesterday.

In most situations, (9) is not acceptable. We can see that there is a clear and outstanding feature of it-clefts: the agreement between the "copular be" and the postcopular constituents. No matter which elements are shown as the "highlighted parts", the subject and "copular be" always remain the same, that is, "it be" ("be" with its singular form). This is the main reason why some scholars regard "it be" as grammatical parts since it will cancel the restrictions on agreement between "copular be" and the postcopular constituent. However, this doesn't put an end to the puzzle of "agreement phenomenon" in it-clefts.

In order to present a more reasonable account of "disagreement" in it-clefts, two concepts are necessarily involved under the field of cognitive grammar. The first one is the term "construal" which is an important concept in cognitive grammar. According to Langacker $(1987,1991,2008)$, an expression's meaning is not just the conceptual content invoked, but also how the content is construed. The notion of construal, in a broader sense, includes specificity, focusing, prominence and perspective (Langacker, 2008, p. 55). Another notion is "bounding". The key points related to the notion of "bounding" are (Langacker, 2008, p. 136-140; Evans \& Green, 2006, p. 557-558):

1) Bounding should not be defined 'within' rather than by the scope of prediction or domain evoked by the expressions; 2) Bounding does not necessarily entail sharp boundaries; 3) Bounding is often a function of construal than of objective realities.

From these points listed above, it is clear that "bounding" is inevitably intertwined with "construal". The concept of bounding provides a good solution for the agreement phenomenon in it-clefts. As shown in (8), the highlighted elements are: proper noun (Xiang Wang), common noun (your sisters), adverbial as position (in the zoo), and adverbial as time (yesterday). "Xiao Wang" as a proper noun like a singular form for a common noun, thus it profiles a thing that is construed as being discretely bounded in some fashion, here "Xiao Wang" as a postcopular complement followed "it was" is grammatically and logically acceptable. However, the plural form "your sisters" shows nothing agreement with the copular be "was", and why? It is the same case to that of the adverbial as position ("in the zoo") or adverbial as time ("yesterday"). How can prepositional phrase (PP), adverbial phrase (AdvP), or in other cases, adjective phrase (AdjP), finite clause, non-finite clause, or other elements, be measured?

It is accepted that in it-clefts "it be" can perfectly agree with any proper elements, but the reason for this is always fuzzy according to previous studies. In this paper we argue that this kind of "disagreement" in it-cleft is inherently "agreement". From (8), we know that no matter what kind the postcopular constituent is, the entrenched part "it be" is almost the same. So it makes clear that the "postcopular constituent" or the "highlighted element" is construed as a bounded entity anyway. In this case, even these traditionally countable nouns like "Xiang Wang"" and "your sisters" are construed as an integrated entity. Therefore, these inherent features of a mass noun, such as homogeneity, contractibility, expansibility and replicability, are included in the integrated entity (Langacker, 2008). These integrated entities are usually "semantic autonomic constituents" which have their own independent semantic status, shown as integral entities. This feature can possibly explain the reason why most of the verbs are excluded from highlighted constituents in it-clefts, especially these transitive verbs since they cannot stand alone as an independent part but with an object. Consider the following instances where the "verbs" are shown as highlighted elements (Xu, 1987, p. 2):

(10) a. John laughed. (Intransitive verb)

b. It was laugh that John did.

c. John helped my brother. (Transitive verb)

d. * It was helped that John my brother.

According to Xu (1987), (10b) is acceptable with regard to "laugh" as an intransitive verb showing a kind of autonomy. But (10d) is unacceptable in that "help" as a transitive verb requiring an object. This explanation is of course far from satisfaction since (10b) could possibly be eligible by converting it into "it was help my brother that John did" and (10d) seems to be artificially created as ungrammatical.

Thus, we shall argue that the predicate verbs can marginally possible be shown as foci. However, it seems that if "the verb" has the possibility of being shown as an independent entity, for example, emerging together with its object, it will have the possibility of serving as a "highlighted constituent" immediately. Unlike the stylistically awkward sentence "it was meeting that I did to your sister in the zoo yesterday", the sentence "it was meeting your sisters that I did in the zoo yesterday" is arguably acceptable. This syntactic account might bring forth another important point that contributes to account for the reason why "predicate verb" cannot usually constitute 
the highlighted element. According to the clausal integration hypothesis (Note 1), the subordinate clause inherits the syntactic properties of a question shown as a clause, but when the predicate verb is fronted as the highlighted element, the rest clausal elements cannot successfully constitute a legal sentence unless adding auxiliaries like "do, did, etc." This might make the sentence more complicated because of a violation of the principle of "linguistic economy", thus it is reluctant to accept in most cases.

Moreover, there is another possible reason: when it-cleft is grammaticalized as a construction, "it be", together with other parts shown as focus-marking device, is semantically weakened and becomes insensitive to grammar. Hence the highlighted constituent is construed as a whole being a prominent entity. But it should be emphasized that it is not wholly because of the grammatical feature or dummy focus marking function that makes "it be" permit different kinds of elements. It is known that "copular be" in it-clefts is always sensitive to modality, aspect and polarity, and words like "may, would, must, will, have to, would, etc." can be used together with "copular be". Some even more mixed forms such as "must have been, had been, etc." can also be possibly applied to substitute "copular be". Meanwhile, "focusing adverbs" (e.g. only, just) may also be inserted between "copular be" and highlighted elements. These phenomena have proved that "copular be" is not totally grammaticalized as a focus marker. So the strategy of considering "copular be" as grammatical marker is not the best way to account for the agreement problem in it-clefts. It seems that it is "construal" by perceiving the highlighted element as an integrated whole that can reasonably interpret this kind of "agreement" in it-clefts. Meanwhile, the element that serves as the foci should be an integrated semantic unit, which constitutes a necessary condition for the eligibility of "foci" in it-clefts.

\subsection{The Highlighted Elements}

A wide range of elements can be generally accepted as highlighted elements (or foci). This part will identify the category of highlighted elements in it-clefts and explain how these constituents can be identified as highlighted elements.

\subsubsection{Identifying the Class of Highlighted Element in It-Clefts}

The highlighted element is considered as the core of it-clefts, thus it is essential to explore the classes and functions represented by the highlighted constituents. Collins (1991, p. 56)'s corpus-based study delicately shows the distribution of different kinds of highlighted elements in it-clefts, as shown in Table 1.

Table 1. The classes and functions of highlighted elements in it-clefts

\begin{tabular}{|c|c|c|c|c|c|c|c|}
\hline $\begin{array}{l}\text { Function } \\
\text { Class }\end{array}$ & Subject & $\begin{array}{l}\text { Direct } \\
\text { Object }\end{array}$ & $\begin{array}{l}\text { Indirect } \\
\text { object }\end{array}$ & Adjunct & Zero & Comp.Prep & Total \\
\hline NP & 280 & 49 & & 26 & & 24 & $379(50.4 \%)$ \\
\hline PP & & & 3 & 159 & & 162 & $162(21.5 \%)$ \\
\hline ZERO & & & & & 109 & & $109(14.5 \%)$ \\
\hline FIN CL & 6 & 2 & & 43 & & & $51(6.8 \%)$ \\
\hline N-F CL & 2 & & & 4 & & & $6(0.8 \%)$ \\
\hline ADV P & & & & 44 & & & $44(5.9 \%)$ \\
\hline ADJ P & 1 & & & & & & $1(0.1 \%)$ \\
\hline
\end{tabular}

As shown in Table1, there are generally seven classes of highlighted elements which are represented in the corpus: noun phrase, prepositional phrase, finite clause, non-finite clause, adverb phrase, adjective phrase and zero. Among all these highlighted elements indicated in the table, the type of highest frequency is the noun phrase taking $50.4 \%$ of the total in the corpus, and the second commonest is the prepositional phrase representing $21.5 \%$ of the total in the corpus. And then comes the zero (without elements), finite clause, adverb phrase, non finite clause and finally adjective phrase. This report is desirably in accordance with Huang (2003)'s investigation. Nominal group and prepositional group, as Huang (2003, p. 93) reports, are most frequently used. Delahunty $(1984$, p. 70$)$ suggests that the class of quantifier phrases and particles can be possibly shown in it-clefts, but as Collins (1991, p. 55) responded, the class of quantifier phrases can almost be included in the adverb phrase and noun phrase and the marginal use of particles as highlighted elements is bounded in the specific contexts.

Identifying the classes of highlighted elements in it-clefts is of great significance to explore the inherent characteristics of it-clefts. The distribution of different classes of highlighted elements is largely grounded in family resemblance. 
As we know, the cognitive categories are made up of prototypes and peripheries. Good and bad examples differ from each other in terms of their categorical status. Wittgenstein (1958) calls "the network of overlapping similarities" as family resemblance. Good examples are the prototypical members, which have the largest numbers of attributes in common with other members of the category and the smallest attributes which also occur with members of neighboring category. In it-clefts, the prototypical numbers are the noun phrase as highlighted elements, which take more than half of the whole amount of it-clefts according to Collins (1991) 's statistics. Another research carried out by some historical scholars like Ball (1991, 1994a,b; Patten, 2012) has reported that the original form of clefts is the noun phrase shown as highlighted element. Therefore, there is a correspondence that the prototypical it-clefts are identical to the original it-clefts. Is this a coincidence?

A common assumption in it-clefts is that one constituent (the cleft constituent) is highlighted whereas the rest of the sentence, realized in a subordinate clause (the clause constituent) presents as the background (also called as presupposition). Moreover, the highlighted/cleft element is expected to receive the main stress, which is phonetically known as the nuclear accent, while the clause constituent is often represented as "given or shared" information (e.g., Chomsky, 1971; Jackendoff, 1972; Huber, 2005; et al.). The prototypical member of it-cleft category, namely, the NP highlighted cleft, generally fulfills most features of it-cleft category. Meanwhile the original clefts known as the NP highlighted one are in accordance with these features as well (Ball, 1991, 1994a, b; Pattern, 2012). This means the historical change of it-clefts do not affect the semantic and pragmatic function of the NP highlighted clefts but merely extend the use of highlighted elements. This evidence is consistent with Lehmann's finding that clefts and pesudoclefts are examples of grammaticalization without lexical bleaching (Traugott, 2008).

\subsubsection{Syntactic Features of Cleft Constituents in It-Clefts}

Linguistic structures are often motivated, that is, a special expression reflects the way one construes a conceived situation. The syntactic linear order always has some effect on meaning since a difference in word order always implies a semantic contrast (though in practical terms it may be slight or even negligible (Langacker, 2008, p. 82). The "inversion" phenomenon is a typical case of changing linear order of the sentence. As in (18):

(11) a. A dead rat lay in the middle of the kitchen floor.

b. In the middle of the kitchen floor lay a dead cat.

According to Langacker, despite (11a) and (11b) have the same constitutive elements, the sentences have different meanings. As we shall know, the semantic contrast in most cases does not reside in the objective situation described but in the way of how it is mentally accessed. In (11b), the location is foregrounded as the prominent part, which directs attention to an already accessible position, then brings the new participant (the dead cat) into the discourse which makes the mental accessing differ from the typical sentential order in (11a).

It-clefts provide the unique option for presenting the information focus in a particular serial order and thus are known as focusing construction which indicates the position of information is "salient" in the information flow. Thus, it-cleft can be generally labeled as a fixed "focal adjusting device". This label is largely based on Langacker's term "focal adjustment" which means "adjust the focus on a particular aspect of any given scene" by using different linguistic expressions or different grammatical constructions to describe that scene (Evans \& Green, 2006, p. 536).

As for it-clefts, different elements of a sentence can be adjusted as the foci for different pragmatic purposes like the example (8). Thus we can say that it-cleft is simply "a usage event" which is defined as "a symbolic expression assembled by a speaker in a particular circumstance for a particular purpose; the pairing of detailed, context-dependent conceptualization and (in case of speech) an actual vocalization" (Langacker, 1987, p. 494). All these individual integrated entities can be shown as the participants (the predicate verb are always excluded as discussed before). Apart from the "highlighted participants (highlighted elements)", other participants might share the same status in the current usage event in it-clefts. Therefore, there are three parts in the usage event represented by it-clefts: grounding elements, highlighted/foregrounding participant and backgrounding participants. For example, in the usage event of "It was Xiao Yang that met your sisters in the zoo yesterday", the status of different parts can be presented below:

Grounding elements:

"it was", "that"

Highlighted participants: "Xiao Yang"

Backgrounding participants: "your sisters", "in the zoo", "yesterday"

The backgrounded participants can be the potential highlighted participants, which can be highlighted for 
pragmatic purposes. Unlike other possible syntactic focus-marking devices such as inversions, right/left dislocations, passives or many others, the "focusing zone" in it-clefts is always fixed, which is selected by many writers/ speakers for linguistic economy or convenience's sake since the use of clefts fulfills a great cognitive principle, namely, least of efforts.

\subsection{The Cleft Clause}

The cleft clause is a relative-like clause since it has some similarly basic properties of a relative clause, but it is not often considered as "relative" with regard to its modifying character. More specifically, the clause in it-clefts modifies the subject "it" not the one before the clause as what an authentic relative clause does. Ball (1994a, p. 604) strongly proposes that "where the focus is a noun phrase, the subordinate clause is plausibly analyzed as a restrictive clause". Later, Ball (1994a, p. 605) posits "where the focus is not an NP, there is little support for a restrictive relative analysis...". Clearly, her analysis is not uncontroversial on this account partly because the relation between highlighted elements and their corresponding cleft clauses are invariably the same, that is, answer vs. question. Lambrecht (2001) proposes that the matrix and the relative clause express a logically simple proposition, which can also be expressed in the form of a single clause without a change in truth conditions. Lambrecht's analysis sincerely represents the traditional consideration of clefts, but what should be noted is that the cleft clause itself can also stand alone as a proposition. In other words, the clause as a relativized question can itself express an independent usage event.

Evidence has demonstrated that, in a typical it-cleft, the "foci" or "highlighted element" is located at a relative stable "prominent" position and "it be" is shown as the "marking cue" "be" performs an assertive identifying function), whereas the cleft clause is situated in the ground as background-settings. This implies that the clausal part in it-clefts is usually reduced into the background status without temporarily prominence compared to the highlighted elements. In contrast, in an atypical it-clefts, the clause could also convey new information, thus it is not unquestionable to report the backgrounding recognition of the clausal part. It is unwise to classify "the foci" and "clause" in terms of information structure when "discourse" is involved. We'd prefer to suggest the elements in it-clefts as a whole constitute an overall usage event. The highlighted constituent and the clause represent different participants in the event. With specific pragmatic purposes or motivations, different aspects like agent, patient, place and time could possibly be adjusted to the "figure" position and receive cognitive prominence.

\section{The Cognitive Motivation of It-Clefts}

It-clefts are focusing constructions by placing different elements into a specific position for conceptual prominence. This coming part will elucidate how the phenomenon of syntactic focusing is realized in it-clefts.

\subsection{Focusing as a Motivation for Linguistic Organization}

Focusing as a general term includes ways of selecting conceptual content for linguistic presentation as well as its organization into what can be generally referred to as "foreground" and "background". Thus, the notion of "attention" or "prominence" is broadly grounded in focusing.

Focusing, as Langacker (2008, p. 57) suggested, is evident in how a lexical item is actually understood in the context of a usage event and a high level of activation is a kind of foregrounding, thus focusing is a matter of degree which is related to the speaker or writer's specific purposes, dimension of linguistic structures and level of organization. Many familiar alignments are grounded in ways of focusing: foreground vs. background, figure vs. ground, profile vs. base, and trajector vs. landmark. On the lexical level, take "cooker" for example, it is a combination of "cook" and "er", i.e. an integration of "an act of cooking" and "the person who undertakes something" together. However, in the lexical item "cooker", none of the combining parts are profiled but peripheral to the overall meaning of "cooker". Yet at a higher level, the combining word is evoked as a whole and the entire entity is foregrounded. On the syntactic level, reordering of the syntactic linear order might cause alternate choices of focusing as in passives, right-dislocations, inversions and clefts.

\subsection{The Function of Focusing in Clefts}

Clefts in English mainly contain the following four types:

(12) a. It was Chinese that we were learning. (It-clefts)
b. All we were learning was Chinese. (All-clefts)
c. What we were learning was Chinese. (What-clefts)
d. The language we were learning was Chinese. (The-clefts)

The four types of clefts are very important syntactic device in English for focusing. Focusing is always 
instantiated by selection of linguistic arrangements, more specifically, word order. In an utterance, new information as focusing part unmarkedly receives more attention than old information or given information. A large number of scholars have summarized some universal principles guiding word order (see Haiman, 1985; Givón, 1988; Croft, 2003):

Principle I: What is old information comes first, what is new information comes later, in an utterance. Principle II: Ideas that are closely connected tend to be placed together.

Principle III: What is the moment uttermost in speaker's mind [less predictable, more important, more intended to be attended to by the hearer] tends to be first expressed.

According to principle I, new information should follow old information. This principle is universally acknowledged as "end focus" principle in information arrangement, which is commonest type in natural language. According to principle III, new information comes before old information. Therefore, principle I and principle III seem to "provide a classic vacuous competing motivation for the ordering of old and new information in utterance" (Croft, 2003, p. 66). Furthermore, principle III seems to pose a threat to principle II as well since fronting of the uppermost information as focusing part may disconnect some conceptually close constituents. It seems as if these principles are contradictory from each other. However, Haiman (1985, p. 238) argues that principle III identifies with linguistic focus which is thus most likely to be the uppermost information in one's mind. In order to make this principle more reasonable, Haiman $(1985$, p. 238) further points out that principle III always applies to information questions only in that the questioned element is in focus and will therefore be traced in the focus position. This point is reasonable since the "interrogative point" always carries new information thus being focused. In general, the principles listed above are not inherently in conflict with each other. For example, principle I and principle III are reconciled with one another with regard to different cognitive adjustments of linguistic structures due to some psychological experiments. According to the Serial Position Effect experiment, people's recall accuracy varies as a function of an item's position within a study list. When asked to recall a list of items in any order (free call), people apt to begin with recalling the end of the list and recall those items best, which is known as Recency Effects; among the earlier list items, the first few items are recalled more frequently than the middle items and this is termed as Primacy Effects (Altmann, 2000).

Given the above psychological effects, It-clefts, all-clefts, what-clefts and the-clefts are a full manifestation of Principle I echoing Recency Effect. Primacy effects are responsible for the reversed counterparts of all-clefts, what-clefts and the-clefts which are labeled as reversed pseudoclefts, shown in (13):

(13) a. Chinese was all we were learning. (Reversed all-clefts)

b. Chinese was what we were learning. (Reversed wh-clefts)

c. Chinese was the language that we were learning. (Reversed the-clefts)

From the above discussion, an interim conclusion can be reached that information distributing characteristics in clefts are largely in accordance with the converging evidence from psychological research which reflect the general cognitive traits of human being. The cognitive basis for producing clefts is conceptual prominence wherein a particular part receives its focusing status as "figure" while another parts are shadowed as "ground". The following part will consider how the figure-ground alignment is realized in it-clefts.

\subsection{Figure-Ground Alignment in It-Clefts}

As indicated earlier, the information distribution in clefts reflects the cognitive characteristics of human being. In brief, the beginning and the end of an expression tend to receive more prominence than other positions. It is known that exploring cognitive functions of a linguistic structure should therefore articulate with what is known about cognitive processing, thus exploring a syntactic structure on a syntactic-semantic level for unfolding the hidden cognitive and psychological features becomes one of the most important tasks for cognitive linguists.

The figure-ground alignment is largely grounded in the notion of focusing. The notion, figure-ground alignment, is derived from Gestalt psychology based on the assumption that human perception appears to automatically segregate any given scene into figure and ground organization. A figure is defined as an entity that possesses a dominant shape which stands out against the ground - the part of a scene that is relegated to the "background". It is generally believed that Cognitive Linguistics is represented by three major approaches: the experiential view, the prominence view and the attentional view of language (Ungerer \& Schmid, 2008). The prominence view provides an explanation of how the information in a clause is selected and arranged. For example, the selection of a subject in a clause is determined by different degrees of prominence carried by the elements involved in a situation, as shown in: 
(14) He looks like Tom.

(15) Tom looks like him.

In (14), "Tom" is set up as a reference point with known information for understanding of "he", and "he" is chosen deliberately as the figure, that is, situated in the prominent position, thus "Tom" is the ground. On the contrary, in (14), "Tom" receives the focus in the prominent position and "he" is shown as the ground. According to Miller (2006), English is unusual in having it-, wh- and reverse-wh clefts. He points out that not all languages in the European areas have clefts of the it-type, or the whole set of pseudoclefts. The typical cleft construction, namely, it-cleft, is formed by placing the "focus" or "highlighted element" into a relative stable "figure" position, and "it be" always shown as the "marking cue"("be" performs an assertive identifying function), and other propositional parts situated in the ground as surroundings. Consider (8) again, we relabelled as (16) for convenience.

(16) a. It was Xiao Yang that met your sisters in the zoo yesterday.

b. It was your sisters that Xiao Yang met in the zoo yesterday.

c. It was in the zoo that Xiao Yang met your sisters yesterday.

d. It was yesterday that Xiao Yang met your sisters in the zoo.

Examples in (16) manifest a typical series of it-clefts. In (16a), subject of the propositional event occupies the "figure" position and becomes focus of the sentence which is thus stressed. The constituent of object, the adverbial of time, the adverbial of place are temporarily reduced into the ground serving as the potential figure. Prominence can be highly selective and the figure-ground organization is not in general automatically determined for a given scene, so it is normally possible to structure the same scene with alternate choices of figure (Langacker, 1987, p. 120). In (16b), (16c), (16d), aspects of object, place and time take up the position of figure and receive cognitive prominence.

\section{Conclusion}

This paper considers the form and function of English it-clefts within the framework of Cognitive Linguistics. Conclusions can be drawn as follows: First, the pronoun "it" in it-clefts together with the cleft clause forms a "discontinuous" description. In other words, the function of the cleft clause is not applied to modify the highlighted element. Instead it is co-referential with the pronoun "it". Second, the copular "be" in it-clefts has the function of "identifying", namely, an identifying verb, which is much contrary to the previous account of "be" as "inert". Third, the highlighted elements in it-clefts denote a thing that can be construed as an integrated whole, thus a transitive verb alone cannot be accepted as a legal member. However, intransitive verbs can be marginally possible in some contexts. Finally, the organization of it-clefts is quite consistent with the psychological effect, i.e. Recency Effect. The highlighted elements are shown as the figure and the cleft clause as the ground providing the known or given information. This paper has fully elaborated the function and motivation of the basic elements in it-clefts, which is in line with the cognitive linguistic tenet that every element in a linguistic structure has its own meaning or meanings.

\section{Acknowledgments}

This paper is supported by the following projects: The Key Project of the Key Research Institute of Humanities and Social Sciences in Chongqing (13SKB023), Project funded by China Postdoctoral Science Foundation (2014M562262), Project funded by Chongqing Postdoctoral Research Foundation (Xm2014011), The Fundamental Research Funds for the Central Universities (SWU1409169) and The Fundamental Research Funds for the Central Universities (SWU0909642).

\section{References}

Akmajian, A. (1970). On deriving cleft sentences from pseudo-cleft sentences. Linguistic Inquiry, 1, 149-68.

Altmann, E. M. (2000). Memory in chains: Modeling primacy and Recency Effects in memory for order. In L. R. Gleitman \& A. K. Joshi (Eds.), Proceedings of the twenty second annual meeting of the Cognitive Science Society (pp. 31-36). Nahwah, NJ: Erlbaum.

Ball, C. N. (1991). The historical development of it-cleft. PhD. Dissertation. Philadelphia: University of Pennsylvania.

Ball, C. N. (1994a). The origins of the informative-presupposition it-cleft. Journal of Pragmatics, 22, 603-628. http://dx.doi.org/10.1016/0378-2166(94)90032-9

Ball, C. N. (1994b). Relative pronouns in it-clefts: The last seven centuries. Language Variation and Change, 6 , 
179-200. http://dx.doi.org/10.1017/S0954394500001630

Chomsky, N. (1970). Remarks on nominalization. In R. A. Jacobs \& P. S. Rosenbaum (Eds.), Reading in English transformational grammar (pp. 184-221). Waltham, Mass.: Ginn.

Collins, P. C. (1991). Cleft and pseudo-cleft constructions in English. London: Routledge. http://dx.doi.org/10.4324/9780203202463

Croft, W. (2003). Typology and Universal (2nd ed.). Cambridge: CUP.

Delahunty, G. (1984). Topics in the syntax and semantics of English cleft sentences. Bloomington, Indiana: Indiana University Linguistics Club.

Dikken, D. M. (2006). Specificational copular sentences and pseudoclefts: A case study. In M. Everaert \& H. V. Riemsdijk (Eds.), The Blackwell Companion to Syntax. Oxford/Malden, MA: Blackwell. http://dx.doi.org/10.1002/9780470996591.ch61

Evans, V., \& Green, M. (2006). Cognitive Linguistics: An Introduction. Edinburgh: Edinburgh University Press.

Gundel, J. K. (1977). Where do cleft sentences come from? Language, 53, 543-49. http://dx.doi.org/10.2307/413176

Haiman, J. (1985). Natural Syntax. Cambridge: Cambridge University Press.

Halliday, M. A. K. (1994). An introduction to functional grammar. London: Arnold.

Harris, A. C., \& Campbell, L. (1995). Historical syntax in cross-linguistic perspective. Cambridge: Cambridge University Press. http://dx.doi.org/10.1017/CBO9780511620553

Hedberg, N. A. (1990). Discourse pragmatics and cleft sentences in English. PhD. Dissertation. Minnesota: University Of Minnesota.

Higgins, F. R. (1979). The pseudo-cleft construction in English. New York: Garland Publishing.

Huang, G. W. (2003). Enhanced theme in English: Its structures and functions. Taiyuan: Shanxi Education Press.

Huang, G. W., \& Fawcett, R. P. (1996). A functional approach to two "focusing" constructions in English and Chinese. Language Sciences, 18(1-2), 179-194. http://dx.doi.org/10.1016/0388-0001(96)00014-9

Huber, S. (2005). The complex functions of it-clefts. In V. Molnar \& S. Winkler (Eds.), The Architecture of Focus (pp. 549-577). Berlin: Walter de Gruyter.

Huddleston, R. (1984). Introduction to the Grammar of English. Cambridge: Cambridge University Press. http://dx.doi.org/10.1017/CBO9781139165785

Jackendoff, R. (1972). Semantic interpretation in Generative Grammar. Cambridge, Massachusetts: MIT Press.

Jespersen, O. (1937/1969). Analytic syntax. New York: Holt, Rinehart and Winston.

Jucker, A. (1996). Book views on Collins' cleft and pseudo-cleft constructions in English. Journal of Pragmatics, 26, 699-710. http://dx.doi.org/10.1016/0378-2166(96)89192-2

Lambrecht, K. (2001). A framework of the analysis of cleft-constructions. Linguistics, 39, 463-516.

Langacker, R. W. (1987). Foundations of cognitive grammar Vol.I: Theoretical prerequisites. Stanford: University of Stanford Press.

Langacker, R. W. (1991). Foundations of cognitive grammar Vol.II: Descriptive Applications. Stanford: University of Stanford Press.

Langacker, R. W. (2008). Cognitive Grammar: A Basic Introduction. Oxford: Oxford University Press. http://dx.doi.org/10.1093/acprof:oso/9780195331967.001.0001

Langacker, R. W. (2009). Investigations in Cognitive Grammar. Berlin: Mouton de Gruyter. http://dx.doi.org/10.1515/9783110214369

Miller, J. (2006). Focus in the languages of Europe. In G. Bernini \& M. L. Schwartz (Eds.), Pragmatic Organization of Discourse in the Languages of Europe (pp. 20-28). Berlin/New York: Mouton de Gruyter. $\mathrm{http}: / / \mathrm{dx}$.doi.org/10.1515/9783110892222.121

Patten, A. (2012). The English It-Cleft: A Constructional Account and a Diachronic Investigation. Berlin: De Gruyter Mouton. http://dx.doi.org/10.1515/9783110279528

Prince, E. (1978). A comparison of wh-clefts and it-clefts in discourse. Language, 54, 883-906. 
http://dx.doi.org/10.2307/413238

Quirk, R., Greenbaum, S., Leech, G., \& Svartvik, J. (1985). A comprehensive grammar of the English language. London: Longman.

Traugott, E. C. (2008). "All that he endeavoured to prove was ...": On the emergence of grammatical constructions in dialogual and dialogic contexts. In R. Kempson \& R. Cooper (Eds.), Language in flux: Variation, change and evolution (pp. 143-177). London: Kings College.

Ungerer, F., \& Schmid, H. J. (1996). An introduction to Cognitive Linguistics. London: Longman.

Wittgenstein, L. (1958). Philosophical Investigation. Oxford: Blackwell.

Xu, S. H. (1987). On English clefts. Shandong Foreign Language Teaching, 3, 1-9.

Yang, K. (2010). Form and meaning of specificational constructions and their motivations. PhD. Dissertation. Chongqing: Southwest University.

\section{Note}

Note 1: The Clausal Integration Hypothesis (Harris \& Campbell, 1995; Yang, 2010; Dikken, 2006) claims that the original NP highlighted it-cleft construction consists of a superordinate clause and a subordinate clause. The NP highlighted constituents as new information represents the answer to an embedded question in the subordinate clause which is currently shown as the presupposition.

\section{Copyrights}

Copyright for this article is retained by the author(s), with first publication rights granted to the journal.

This is an open-access article distributed under the terms and conditions of the Creative Commons Attribution license (http://creativecommons.org/licenses/by/3.0/). 